\title{
Years of life lost of inhabitants of rural areas in Poland due to premature mortality caused by external reasons of death 1999-2012
}

\author{
Marek Bryła', Irena Maniecka-Bryła², Monika Burzyńska², Małgorzata Pikala ${ }^{2}$ \\ ${ }^{1}$ Department of Social Medicine, Chair of Social and Preventive Medicine, Medical University, Lodz, Poland \\ ${ }^{2}$ Department of Epidemiology and Biostatistics, Chair of Social and Preventive Medicine, Medical University, Lodz, Poland
}

Bryła M, Maniecka-Bryła I, Burzyńska M, Pikala M. Years of life lost of inhabitants of rural areas in Poland due to premature mortality caused by external reasons of death 1999-2012. Ann Agric Environ Med. 2016; 23(4): 598-603. doi: 10.5604/12321966.1226853

\begin{abstract}
Introduction. External causes of death are the third most common causes of death, after cardiovascular diseases and malignant neoplasms, in inhabitants of Poland. External causes of death pose the greatest threat to people aged 5-44, which results in a great number of years of life lost.

Objective. The aim of the study is the analysis of years of life lost due to external causes of death among rural inhabitants in Poland, particularly due to traffic accidents and suicides.

Material and methods. The study material included a database created on the basis of 2,100,785 certificates of rural inhabitants in Poland in the period 1999-2012. The SEYLL (Standard Expected Years of Life Lost per living person) and the $\mathrm{SEYLL}_{d}$ (per death) indices were used to determine years of life lost due to external causes of death. Joinpoint models were used to analyze time trends.

Results. In the period 1999-2012, 151,037 rural inhabitants died due to external causes, including 27.2\% due to traffic accidents and $25.2 \%$ due to suicides. In 2012, the SEYLL was 1,817 per 100,000 males and 298 per 100,000 females. Among males, suicides $\left(S E Y L L_{p}=633\right.$ years per 100,000) and traffic accidents $\left(S E Y L L_{p}=473\right.$ years per 100,000) contributed to the largest number of years of life lost. Among females, SEYLL values were: 109 years due to traffic accidents and 69 years due to suicides (per 100,000). Among males, SEYLL values started to decrease in 2008 at the average annual rate of $3.2 \%$. In the group of females in the period 1999-2012, SEYLL values were decreasing by $2.4 \%$ per year.

Conclusions. The decreasing trend of the number of lost years of life due to external causes among rural inhabitants does not apply to suicides among men. The SEYLL due to this group of causes has been steadily increasing since 1999 . Analysis of the years of life lost focuses on the social and economic aspects of premature mortality due to external causes.
\end{abstract}

\section{Key words}

external reasons of death, suicides, traffic accidents, years of life lost, Poland

\section{INTRODUCTION}

Epidemiological studies indicate that there are huge health inequalities in different social groups. Major factors which contribute to those inequalities include socio-economic and the environment in which the person lives $[1,2]$. Health measures can be applied to estimate further life expectancy for the year 2013 in male urban and rural inhabitants. This allows the conclusion that male urban inhabitants lived longer than males from rural areas in all provinces, except for Silesia, and the greatest differences were observed in the West Pomeranian (2.7 years), Mazovian (2.6 years) and Lublin (2.5 years) provinces [3]. With regards to females differences in the lifespan of urban and rural inhabitants were much smaller. In 13 provinces, the urban inhabitants lived longer than rural inhabitants (the greatest difference, i.e. 1.5 years, was observed in the West Pomeranian Province). In the Lesser Poland Province, no differences were noted between the city and the countryside, and in 2 provinces Lodz and Silesia - female rural inhabitants lived longer. The average further life expectancy in Poland was 73.5 years for

Address for correspondence: Prof. Irena Maniecka-Bryła, MD, PhD, Head of the Department of Epidemiology and Biostatistics, Chair of Social and Preventive Medicine, Medical University, Zeligowskiego 7/9, 90-752 Lodz, Poland

E-mail: irena.maniecka-bryla@umed.lodz.pl

Received: 30 December 2015; accepted: 28 June 2016 the countryside and 72.4 years for the city. In females, the further average life expectancy, both for urban and rural inhabitants, was 81.1 years in 2013 .

Analysis of proportional mortality indicates that cardiovascular diseases, malignant neoplasms and external reasons contributed to the highest number of deaths in 2013 (46.1\%, 24.6\% and $6.1 \%$ of the total number of deaths respectively). External causes posed the highest threat to life to people aged 5-44 years. They contributed to $42 \%$ of deaths [4] and, as a consequence, to the greatest number of years of life lost $[5,6,7]$. In the group of external causes, the most common were traffic accidents (17.9\%) and suicides (27.7\%). They were responsible for almost half of the deaths in the inhabitants of Poland. These two causes contributed to the highest number of lost years of life per one person who died from that cause [8].

Measures which are used to evaluate mortality in units of lost years of life are more and more useful in the assessment of health of a population. They are better than any previously applied mortality rates because they more efficiently reflect the social and economic aspects of losses related to premature mortality. From the economic point of view, the most effective are preventive activities aiming at reducing deaths which contribute to the highest number of lost years of life. 


\section{OBJECTIVE}

The aim of the study was the analysis of years of life lost due to external causes of death among rural inhabitants in Poland, particularly due to traffic accidents and suicides in the period 1999-2012.

\section{MATERIALS AND METHODS}

The research project was granted the approval of the Bioethics Committee of the Medical University of Lodz on 22 May 2012 (No. RNN/422/12/KB).

The study material included a database which contains information gathered from 2,100,785 death certificates of ruralinhabitants in Poland who died between 1 January 1999 - 31 December 2012, provided by the Department of Information of the Central Statistical Office for the purpose of this study. In order to calculate the death rates, data on the size of population of Poland on 31 December of the particular year was used. To eliminate the influence of any age differences on the mortality rate and compare the time and location of deaths, SDRs was calculated according to the standard European population. The standardization procedure was carried out with the direct method.

In Poland, since 1 January 1997, causes of death are coded according to the International Statistical Classification of Diseases and Health Related Problems - Tenth Revision ICD-10. In that classification, external causes of morbidity and mortality (V01-Y98) include: transport accidents (V01-V99), other external causes of accidental injury (W00-X59), intentional self-harm (X60-X84), assault (X85-Y09), other (e.g. event of undetermined intent, legal intervention and operations of war, complications of medical and surgical care).

Years of life lost were counted and analyzed by the method described by Christopher Murray and Alan Lopez in Global Burden of Disease (GBD) [9]. The SEYLL index (Standard Expected Years of Life Lost) is used to calculate the number of years of life lost by the studied population in comparison to the years lost by the referential (standard) population. a mortality standard norm was applied, according to Murray and Lopez, based on the Coale-Demenywest model life table which has a life expectancy at birth of 80 years for males and 82.5 years for females [10].

A population of size $\mathrm{N}$ should considered and assume that $\mathrm{d}_{\mathrm{xc}}$ stands for the number of deaths at the age of $x$ due to a particular cause $c$, and is the number of expected years of life that remain to be lived by the population which is at the age of $x$. If it is assumed that $l$ is the last year of age until which the population lives, the number of years of life lost due to the cause $c$ is calculated with the use of the following formula:

$$
S E Y L L=\sum_{x=0}^{l} d_{x c} e_{x}
$$

By dividing the absolute number of years lost due to cause $c$, calculated according to the following formula, by the number of deaths due to cause $c$, the average number of years of life lost by one person who died due to cause $c$ is obtained:

$$
S E Y L L_{d}=\frac{\sum_{x=0}^{l} d_{x c} e_{x}}{\sum_{x=0}^{l} d_{x c}}
$$

The SEYLL indices determined by the number of the studied population [11] was also estimated:

$$
S E Y L L_{p}=\frac{\sum_{x=0}^{l} d_{x c} e_{x}}{N}
$$

Analysis of time trends was carried out with joinpoint models. The Joinpoint Regression Programm is a statistical software package developed by the US National Cancer Institute for the Surveillance, Epidemiology and End Results Program. The software takes trend data and fits the simplest joinpoint model that the data allow. The user supplies the minimum and maximum number of joinpoints. The program starts with the minimum number of joinpoint (e.g. 0 joinpoints, which is a straight line) and tests whether more joinpoints are statistically significant and must be added to the model (up to that maximum number). This enables the user to test that an apparent change in trend is statistically significant $(\mathrm{p}<0.05)$. The tests of significance use a Monte Carlo Permutation method [12].

Also calculated was the annual percentage change (APC) for the indices: SEYLL $L_{p}$ and SEYLL for each segment of broken lines with corresponding $95 \%$ confidence intervals (CI).

\section{RESULTS}

In 1999-2012, 151,037 inhabitants of rural areas in Poland died due to external causes, proportional mortality ratio - 7.2\%. In 2012, the standardized mortality ratios due to external causes were 105.3 per 100,000 males and 21.6 per 100,000 females (Tab. 1). More than half of the deaths were caused by traffic accidents (27.2\%) and suicides (25.2\%). The standardized mortality ratios due to traffic accidents in 2012 were 21.5 per 100,000 males and 5.3 per 100,000 females, whereas due to suicides the values were 34.9 per 100,000 males and 4.1 per 100,000 females.

Table 1. Standardized death rates due to external causes divided into

\begin{tabular}{|c|c|c|c|c|c|c|}
\hline \multirow[b]{2}{*}{ Year } & \multicolumn{3}{|c|}{ Males } & \multicolumn{3}{|c|}{ Females } \\
\hline & $\begin{array}{l}\text { external } \\
\text { causes }\end{array}$ & $\begin{array}{c}\text { traffic } \\
\text { accidents }\end{array}$ & suicides & $\begin{array}{c}\text { external } \\
\text { causes }\end{array}$ & $\begin{array}{c}\text { traffic } \\
\text { accidents }\end{array}$ & suicides \\
\hline 1999 & 131.8 & 42.5 & 32.2 & 29.7 & 8.5 & 5.1 \\
\hline 2000 & 123.6 & 40.9 & 31.6 & 27.9 & 7.8 & 4.7 \\
\hline 2001 & 115.9 & 33.7 & 30.6 & 26.6 & 7.4 & 4.3 \\
\hline 2002 & 117.4 & 35.2 & 30.5 & 26.9 & 7.6 & 5.1 \\
\hline 2003 & 115.2 & 33.1 & 31.1 & 24.3 & 7.0 & 4.7 \\
\hline 2004 & 116.1 & 34.4 & 31.7 & 24.2 & 7.5 & 4.6 \\
\hline 2005 & 117.5 & 32.2 & 31.9 & 24.3 & 6.9 & 4.4 \\
\hline 2006 & 115.4 & 30.1 & 31.1 & 24.2 & 6.5 & 4.2 \\
\hline 2007 & 116.8 & 33.0 & 28.6 & 23.3 & 7.4 & 4.0 \\
\hline 2008 & 118.2 & 31.4 & 31.7 & 24.6 & 7.6 & 4.1 \\
\hline 2009 & 109.6 & 26.3 & 34.9 & 23.5 & 6.1 & 5.3 \\
\hline 2010 & 109.4 & 23.7 & 35.5 & 20.8 & 5.3 & 4.1 \\
\hline 2011 & 109.2 & 25.5 & 34.6 & 21.6 & 5.6 & 3.9 \\
\hline 2012 & 105.3 & 21.5 & 34.9 & 21.6 & 5.3 & 4.1 \\
\hline
\end{tabular}
traffic accidents and suicides by gender among rural inhabitants in Poland 1999-2012 (per 100,000) 
The number of deaths due to external causes significantly depended on the age and gender of the person. In 2012, in the group of females, deaths due to external causes made up $3 \%$ of the total number of deaths, and for the male group the percentage was $10.3 \%$. The standardized mortality ratio due to external causes is very high in younger people and gradually decreases with age (Fig. 1), which directly results in a huge number of years of life lost due to external causes, mostly due to traffic accidents and suicides.

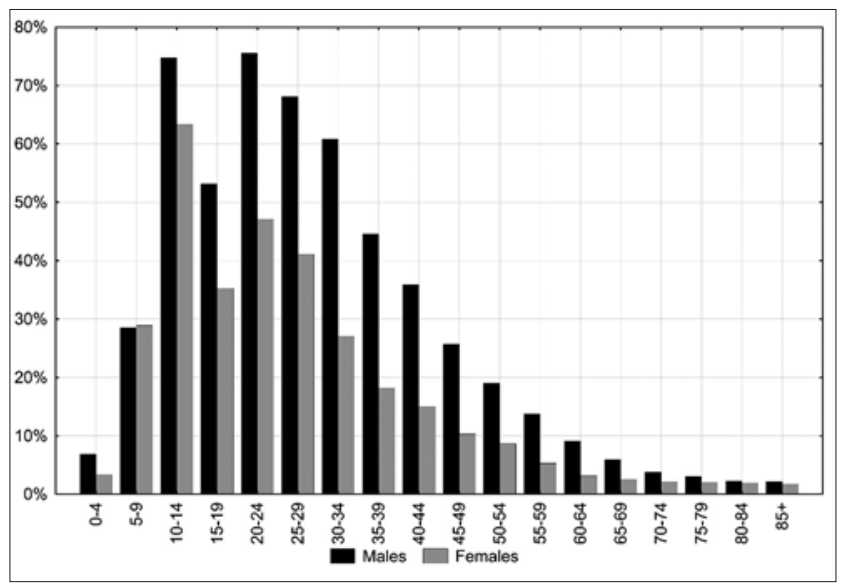

Figure 1. Proportion of death due to external causes by gender and age groups among rural inhabitants in Poland 1999-2012

In 2012, the absolute number of years of lost life (SEYLL) in rural inhabitants was 137,703 in the male group and 22,670 in the female group. The SEYLL index was 1,817 per 100,000 males and 298 per 100,000 females. In urban inhabitants, the values of the SEYLL index were lower in 2012 (1,359 per 100,000 males and 279 per 100,000 females). The SEYLL index showed that every male inhabitant living in the countryside who died in 2012 due to external causes, on average, lost 16.5 years of life, and a female from this area, on average, lost 10.9 years. The values of the SEYLL $\mathrm{d}_{\mathrm{d}}$ index were even higher with regards to traffic accidents (20.9 for males and 18.9 for females) and suicides (17.2 for males and 15.4 for females) (Tab. 2).

Table 2. Years of life lost due to external causes of death, including traffic accidents and suicides in inhabitants of city and rural areas in Poland in 2012

\begin{tabular}{|c|c|c|c|c|c|c|}
\hline & & Rural & & & Urban & \\
\hline $\begin{array}{l}\text { Causes of } \\
\text { death }\end{array}$ & SEYLL & $\begin{array}{c}\text { SEYLL }_{p} \text { (per } \\
100,000)\end{array}$ & $\mathrm{SEYLL}_{\mathrm{d}}$ & SEYLL & $\begin{array}{c}\text { SEYLL }_{p}(\text { per } \\
100,000)\end{array}$ & SEYLL $_{d}$ \\
\hline \multicolumn{7}{|l|}{ Males } \\
\hline $\begin{array}{l}\text { external } \\
\text { causes }\end{array}$ & 137,703 & 1817 & 16.5 & 150437 & 1359 & 15.6 \\
\hline \multicolumn{7}{|l|}{ including: } \\
\hline $\begin{array}{l}\text { traffic } \\
\text { accidents }\end{array}$ & 35,867 & 473 & 20.9 & 27828 & 251 & 18.7 \\
\hline suicides & 47,988 & 633 & 17.2 & 47922 & 433 & 17.4 \\
\hline \multicolumn{7}{|l|}{ Females } \\
\hline $\begin{array}{l}\text { external } \\
\text { causes }\end{array}$ & 22,670 & 298 & 10.9 & 34183 & 279 & 9.8 \\
\hline \multicolumn{7}{|l|}{ including: } \\
\hline $\begin{array}{l}\text { traffic } \\
\text { accidents }\end{array}$ & 8,283 & 109 & 18.9 & 7579 & 62 & 14.8 \\
\hline suicides & 5,235 & 69 & 15.4 & 6749 & 55 & 14.4 \\
\hline
\end{tabular}

Both the absolute number of years of lost life, as well as the SEYLL and the SEYLL ${ }_{\mathrm{d}}$ indices for external causes, have been decreasing since 1999 (Tab. 3). Between 1999-2001, the SEYLL index was decreasing by $7 \%$ and after 2001 slightly increased, i.e. by $0.1 \%$; since 2008 , an annual average decrease in the value of the index has been observed: $-3.2 \%$. With regards to females, over the whole study period the SEYLL index was gradually decreasing with an annual decrease of $-2.4 \%$ (Tab. 4). The number of lost years of life per 1 rural inhabitant who died from external reasons also decreased. In the male group, the annual decrease was $-0.9 \%$ and in the female group: $-2.1 \%$ (Tab. 5).

A more detailed analysis of reasons showed that there are huge differences in the trends and pace of changes in the number of lost years of life due to traffic accidents and suicides in 1999-2012. In the male group, the SEYLL index values due to traffic accidents were decreasing annually, on average by $-3.7 \%$, and due to suicides the values were

Table 3. Years of life lost due to external causes of death in absolute numbers (SEYLL), ratios per 100,000 population (SEYLL) and ratios per one person who died from that cause $\left(S E Y L L_{d}\right)$ by gender in inhabitants of rural areas in Poland 1999-2012

\begin{tabular}{ccccccc}
\hline \multirow{2}{*}{ Year } & \multicolumn{3}{c}{ Males } & \multicolumn{3}{c}{ Females } \\
\cline { 2 - 7 } & SEYLL & $\begin{array}{c}\text { SEYLL } \\
(\text { per 100,000) }\end{array}$ & SEYLL & SEYLL & $\begin{array}{c}\text { SEYLL }_{p} \\
(\text { per 100,000) }\end{array}$ & SEYLL $_{d}$ \\
\hline 1999 & 175011 & 2408 & 19.1 & 31504 & 431 & 12.2 \\
\hline 2000 & 159384 & 2192 & 18.5 & 29173 & 398 & 11.9 \\
\hline 2001 & 149853 & 2058 & 18.4 & 28347 & 386 & 12.1 \\
\hline 2002 & 152610 & 2092 & 18.3 & 28840 & 392 & 12.0 \\
\hline 2003 & 150742 & 2062 & 18.2 & 26191 & 355 & 12.1 \\
\hline 2004 & 151281 & 2066 & 17.9 & 26415 & 358 & 12.0 \\
\hline 2005 & 154166 & 2102 & 17.9 & 26097 & 353 & 11.7 \\
\hline 2006 & 151761 & 2067 & 17.7 & 25487 & 344 & 11.4 \\
\hline 2007 & 153765 & 2089 & 17.6 & 26237 & 353 & 6.1 \\
\hline 2008 & 155470 & 2105 & 17.4 & 27888 & 374 & 12.3 \\
\hline 2009 & 146640 & 1980 & 17.5 & 25675 & 343 & 5.9 \\
\hline 2010 & 144107 & 1913 & 16.9 & 21973 & 290 & 11.1 \\
\hline 2011 & 146104 & 1934 & 17.0 & 23175 & 305 & 11.3 \\
\hline 2012 & 137703 & 1817 & 16.5 & 22670 & 298 & 10.9 \\
\hline
\end{tabular}

Table 4. SEYLL time trends by gender in inhabitants of rural areas in Poland 1999-2012 - joinpoint regression analysis

\begin{tabular}{lccccc}
\hline Causes of death & $\begin{array}{c}\text { Join- } \\
\text { points }\end{array}$ & Period & APC & \multicolumn{2}{c}{$95 \% \mathrm{Cl}$} \\
\hline Males & \multicolumn{1}{c}{$1999-2001$} & $-7.1^{*}$ & -11.6 & -2.4 \\
\hline external causes of death & 2 & $2001-2008$ & 0.1 & -0.7 & 1.0 \\
\hline including: & & $2008-2012$ & $-3.2^{*}$ & -4.7 & -1.7 \\
\hline traffic accidents & 0 & $1999-2012$ & $-3.7^{*}$ & -4.8 & -2.6 \\
\hline Suicides & 0 & $1999-2012$ & $1.0^{*}$ & 0.2 & 1.7 \\
\hline Females & 0 & $1999-2012$ & $-2.4^{*}$ & -3.1 & -1.7 \\
\hline external causes of death & 0 & & & -2.7 \\
\hline including: & 0 & $1999-2012$ & $-3.4^{*}$ & -4.7 & -2.0 \\
\hline traffic accidents & 0 & $1999-2012$ & -1.0 & -2.1 & 0.2 \\
\hline suicides & & & &
\end{tabular}

${ }^{*} p<0.05$ 
Table 5. SEYLL time trends by gender in inhabitants of rural areas in Poland 1999-2012 - joinpoint regression analysis

\begin{tabular}{|c|c|c|c|c|c|}
\hline Causes of death & $\begin{array}{l}\text { Join- } \\
\text { points }\end{array}$ & Period & APC & \multicolumn{2}{|c|}{$95 \% \mathrm{Cl}$} \\
\hline \multicolumn{6}{|l|}{ Males } \\
\hline external causes of death & 0 & 1999-2012 & $-0.9 *$ & -1.0 & -0.8 \\
\hline \multicolumn{6}{|l|}{ including: } \\
\hline traffic accidents & 0 & 1999-2012 & -0.1 & -0.3 & 0.1 \\
\hline Suicides & 0 & 1999-2012 & $-0.8^{*}$ & -0.9 & -0.6 \\
\hline \multicolumn{6}{|l|}{ Females } \\
\hline external causes of death & 0 & 1999-2012 & -2.1 & -5.4 & 1.3 \\
\hline \multicolumn{6}{|l|}{ including: } \\
\hline traffic accidents & 0 & 1999-2012 & -2.0 & -5.7 & 1.7 \\
\hline Suicides & 0 & 1999-2012 & -1.8 & -5.2 & 1.7 \\
\hline
\end{tabular}

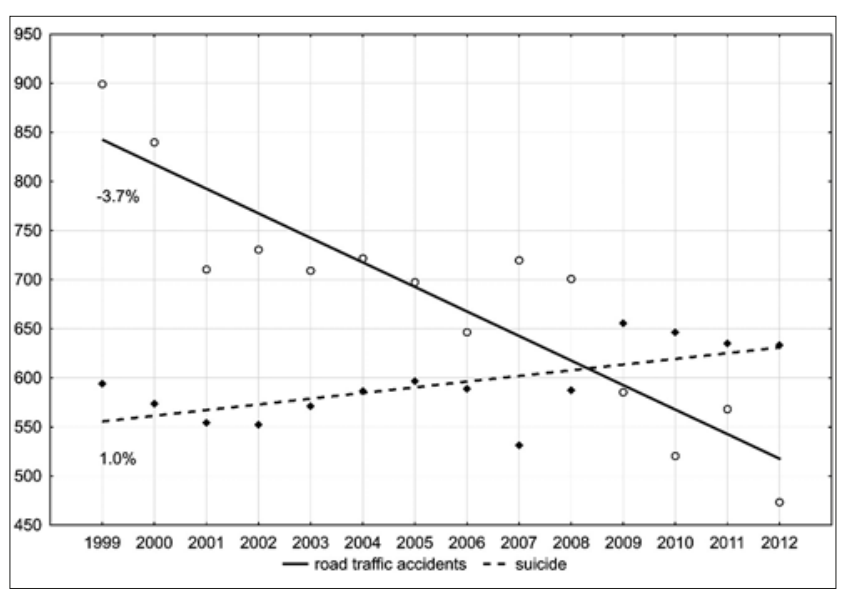

Figure 2. Time trends in SEYLL of males due to road traffic accidents and suicide among rural inhabitants of Poland 1999-2012 (per 100,000 males)

increasing at $1 \%$ per year (Fig. 2). Since 2009, the number of years of life lost due to suicides in males has been higher than due to traffic accidents. In 2012, the SEYLL index values were 473 years due to traffic accidents and 633 years due to suicides per 100,000 males - inhabitants of rural areas in Poland. The above observation can be compared to the SEYLL index values for city dwellers. In cities, these indices in $2012^{p}$ were 251 per 100,000 males due to traffic accidents and 433 due to suicides (Tab. 2).

With regards to females, the SEYLL index was decreasing for both traffic accidents and suicides; however, the decrease pace was much higher for traffic accidents (-3.4\% vs. $1.0 \%)$; thus, the difference is gradually reducing (Fig. 3). In 2012, the SEYLL index was: 109 years due to traffic accidents and 69 due to suicides per 100,000 females - inhabitants of rural areas in Poland. In cities, the values were 62 due to traffic accidents and 55 due to suicides.

\section{DISCUSSION}

Results of studies on differences in health between urban and rural inhabitants published worldwide are ambiguous. Wealth, level of urbanization and industrialization in particular countries are factors which affect health and the environment, and vary in different countries [13]. In

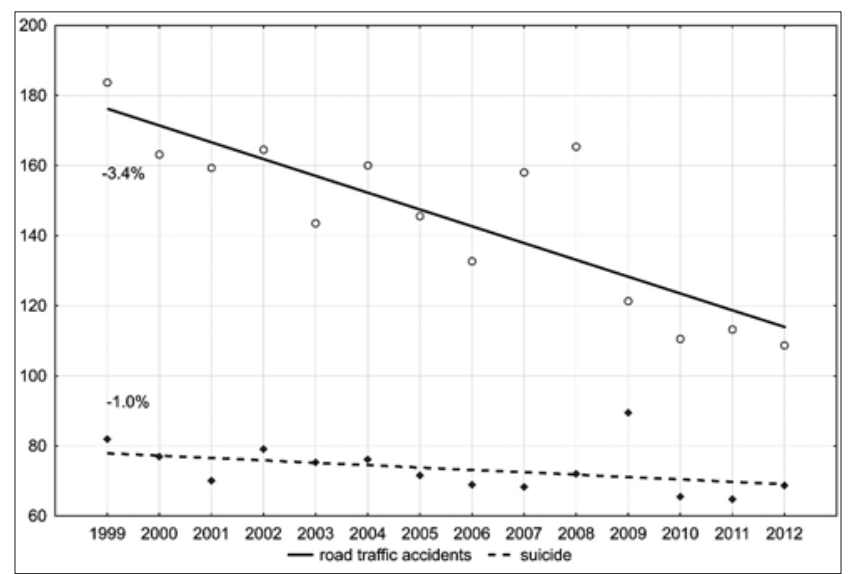

Figure 3. Time trends in SEYLL of females due to road traffic accidents and suicide among rural inhabitants in Poland 1999-2012 (per 100,000 females)

eastern European countries, rural inhabitants are less healthy than urban inhabitants $[14,15,16,17]$. In most western European countries, Scandinavia and the USA, the trend is different - people living in the countryside enjoy better health. This refers particularly to younger populations [18]. In the presented study it was observed that in countries where the rural inhabitants are poor and feel they cannot be provided with basic needs, they are less healthy than urban dwellers $[19,20]$.

In 2013, the Main Statistical Office in Poland conducted a study 'European Union Statistics on Income and Living Conditions' (EU-SILC). Its authors gathered information on the income of households in Poland in 2012 by applying a methodology adopted by the Eurostat which used so called 'equivalized disposable income' in evaluating the financial situation of a household [21]. To a great extent, the income depended on the living place. With regards to inhabitants of the countryside, the average equivalized disposable income was 20,832 PLN and constituted $83.3 \%$ of the national average salary, which was 25,007 PLN in cities (population $100,000-500,000)-28,771$ PLN (115.1\% of the national average salary), whereas in big cities (population of 500,000 or more) the equivalized disposable income was 34,598 PLN and constituted $138.4 \%$ of the national average salary.

In comparison to European Union countries (UE-28), the at-risk-of-poverty and social-exclusion rates in Poland are slightly above the average rate (25.8\% for Poland and $24.5 \%$ for the EU-28). However, the value in Poland is slowly and gradually decreasing. Since 2005 , it has dropped by $19.5 \%$. From the point of view of regions, the most negative trends were observed in the eastern part of the country (30.6\% of the population are at risk of poverty or social exclusion). It can be concluded that the risk of poverty or social exclusion increases along with a decrease in the population. Thus, the worst situation can be observed in the countryside (32.1\%).

A comparative analysis of the health of urban and rural inhabitants in Poland indicates that the greatest differences in mortality is with regard to external causes of death, first and foremost traffic accidents and suicides [4], and from this aspect the countryside is at a disadvantage. The total number of years of life lost due to external causes of death in 2011 was 1,610 per 100,000 males and 290,000 per 100,000 females. Of this number, males lost 410 years and females lost 90 years in traffic accidents, and with regards to suicides the numbers of lost years of life were 500 for males and 60 for females [8]. 
The findings of the current study indicate that all the above rates were higher for rural inhabitants than the mean results for Poland. The most noticeable difference was observed for males who lost years of life in suicidal attempts. The SEYLL index for rural inhabitants, on average, was $26 \%$ higher than for other Polish inhabitants.

For some years in Poland, mortality due to suicide has been higher than that due to traffic accidents. Suicides result from a complex interaction between psychic disorders, such as affective disorders, addictions and social and economic factors [22]. The standardized mortality ratio due to suicide increased in Poland between 1970-2009 from the value 11.2 to 17.0 (by $51.3 \%$ ). Such a huge increase contrasts with trends observed in other European countries in which the number of suicides has dropped since the beginning of the 1990s. Many researchers point out that the reason for this increase might have been the fact that many ex-communist countries concealed the problem of suicide. In Poland, the data on this issue, dating back to the period before 1989, has never been analyzed $[23,24]$.

An increase in the number of suicides in males contributes to a growing mortality trend due to these reasons. In the female group, the value of the mortality rate between 1970-2010 remained more or less on a similar level. This trend resulted in the highest male-to-female suicide ratio in Europe, i.e. 7:1 One of causes for such huge differences might be the fact that women, more often than men, use so-called 'soft' suicide methods, such as poisoning or drowning. This could lead to a wrong classification of the cause of death [25]. However, it is beyond any doubt that men are more prone to commit suicide and to be affected by so- called 'male depression'. Men more often than women suffer from stress, become addicted to alcohol and less frequently ask for help. Such problems are particularly visible in eastern European countries where social and economic changes, as well as increased unemployment, lead to fewer opportunities for males and their social exclusion $[26,27]$. Women are not affected by the above negative social phenomena to such extent as men. They are protected by maternity duties, use social help more often than males, and are less prone to take risk and become addicted to alcohol [28].

Despite the decrease in the number of deaths due to traffic accidents, the death rate in Poland due to the above reason is still one of the highest in Europe. In 2010, a higher mortality rate was observed only in Romania [29]. The bad condition of roads, poor technical condition of vehicles and reckless driving, especially exceeding speed limits and drink-driving, contributed to a great number of traffic victims [30]. Traffic accidents are the most common reason for death in people under 25 years of age [3]. According to the WHO, 75\% of people involved in traffic accidents are men. The difference is even more visible in people aged 15-29, where males make up $80 \%$ of the total number of victims. This results from the fact that the majority of drivers are males and they more often use vehicles which are involved in accidents, e.g. motorbikes. They also exceed speed limits more often than women and drive under the influence of alcohol [31]. It is worth noting that data on premature mortality in the period 2002-2011 were analysed by Polish authors with the use of PYLL (potential years of life lost) methodology. Rural/urban ratio was used to present the differences in premature mortality between rural and urban areas. Premature mortality among men in rural areas was significantly higher than in urban areas for all analysed causes of death. The biggest differences were due to external causes, suicides and traffic accidents [32].

\section{CONCLUSIONS}

1. Analysis of the years of life lost emphasizes social and economic aspects of losses caused by premature mortality due to external causes.

2. The decrease in the number of lost years of life in Poland due to external causes do not refer to male suicide. The SEYLL index value due to the above cause has been gradually increasing since 1999 .

3. There is a need to prepare and implement pedagogical and psychological programmes, first of all, for young males rural inhabitants, which will help enable coping in difficult situations and actively seek help.

\section{Funding}

The study was financed by the National Science Centre (DEC2013/11/B/HS4/00465).

\section{Authors' contributions}

Conception and design of the study: IMB MP MBu. Performance of the study: MP MBu IMB. Data analysis: Writing the study: MP. Bibliography search and analysis: MB MP. Revision of the draft: IMB. All authors read and approved the final manuscript.

\section{REFERENCES}

1. Fogelholm M, Valve R, Absetz P, Heinonen H, Uutela A, Patja K, et al. Rural-urban differences in health and health behavior: A baseline description of a community health-promotion programme for the elderly. Scand J Public Health. 2006; 34(6): 632-640.

2. Maniecka-Bryla I, Pikala M, Bryla M. Health inequalities among rural and urban inhabitants of Lodz Province, Poland. Ann Agric Environ Med. 2012; 19(4): 723-731.

3. Bank danych lokalnych. http://www.stat.gov.pl (access: 2015.04.26).

4. Wojtyniak B, Goryński P, Moskalewicz B. Sytuacja zdrowotna ludności Polski i jej uwarunkowania. Warszawa: Narodowy Instytut Zdrowia Publicznego - Państwowy Zakład Higieny, 2012. (in Polish)

5. Pikala M, Bryla M, Bryla P, Maniecka-Bryla I. Years of life lost due to external causes of death in the Lodz province, Poland. PLoS One. 2014; 9(5): e96830. doi: 10.1371/journal.pone.0096830.

6. Maniecka-Bryla I, Pikala M, Bryla M. Life years lost due to cardiovascular diseases. Kardiol Pol. 2013; 71(10): 893-900.

7. Pikala M, Maniecka-Bryla I. Years of life lost due to malignant neoplasms characterized by the highest mortality rate. Arch Med Sci. 2014; 10(5): 999-1006. doi: 10.5114/aoms.2013.36237

8. Maniecka-Bryla I, Bryla M, Bryla P, Pikala M. The burden of premature mortality in Poland analysed with the use of standard expected years of life lost. BMC Public Health. 2015; 15: 101 doi:10.1186/s12889-0151487-x.

9. Murray CJL, Lopez A. Global burden of diseases. Vol. 1. Warsaw: University Medical Publishing House "Vesalius", 2000.

10. Murray CJ, Ahmad OB, Lopez AD, Salomon JA. WHO System of Model Life Tables. http://www.who.int/healthinfo/paper08.pdf. (access: 2015.12.28).

11. Marshall RJ. Standard Expected Years of Life Lost as a measure of disease burden: An investigation of its presentation, meaning and interpretation. In:Preedy VR, Watson RR (eds.). Handbook of disease burdens and quality of life measures, Berlin 2009. p.3421-3434.

12. Kim H, Fay MP, Feuer EJ, Midthune DN. Permutation tests for joinpoint regression with applications to cancer rates. Stat Med. 2000; 19(3): $335-351$.

13. Verheij RA. Explaining urban-rural variations in health: a review of interactions between individual and environment. Soc Sci Med. 1996; 42(6): 923-935. 
14. Gilmore A, McKee M, Rose R. Determinants of and inequalities in self-perceived health in Ukraine. Soc Sci Med. 2002; 55(12): 2177-2188

15. Kalediene R, Petrauskiene J. Socio-economic transition, inequality, and mortality in Lithuania. Econ Hum Biol. 2004; 2(1): 87-95.

16. Leinsalau M. Social variation in self-rated health in Estonia: a crosssectional study. Soc Sci Med. 2002; 55(5): 847-861.

17. Powles J, Kirov P, Feschieva N, Stanoev M, Atanasova V. Stroke in urban and rural populations in north-east Bulgaria: incidence and case fatality findings from a 'hot pursuit' study. BMC Public Health. 2002; 2(24) doi:10.1186/1471-2458-2-24.

18. Mainous A, Kohrs F. A comparison of health status between rural and urban adults. J Community Health.1995; 20(5): 423-431.

19. Senior M, Wiliams H, Higgs G. Urban-rural mortality differentials: controlling for material deprivation. Soc Sci Med. 2000; 51(2): 289-305

20. Stafford M, Marmot M. Neighborhood deprivation and health: does it affect us all equally? Int J Epidemiol. 2003; 32(3): 357-366.

21. Europejskie badaniedochodów i warunków życia (EU-SILC) w 2013 roku. http://stat.gov.pl/obszary-tematyczne/warunki-zycia/dochodywydatki-i-warunki-zycia-ludnosci/europejskie-badanie-dochodowi-warunkow-zycia-eu-silc-w-2013-r-,7,5.html (access: 2015.12.15) (inPolish)

22. Hawton K, van Heeringen K.Suicide. Lancet. 2009; 373(9672): 1372 1281.

23. Höfer P, Rockett IR, Värnik P, Etzersdorfer E, Kapusta ND. Forty years of increasing suicide mortality in Poland: undercounting amidst a hanging epidemic? BMC Public Health. 2012; 12: 644. doi 10.1186/14712458-12-644.
24. Mäkinen IH. Suicide mortality of Eastern European regions before and after the Communist period. Soc Sci Med. 2006; 63(2): 307-319.

25. Rockett IR, Kapusta ND, Bhandari R. Suicide misclassification in an international context: revisitation and update. Suicidol Online. 2011; 2: 48-61.

26. Möller-Leimkühler AM. The gender gap in suicide and premature death or: why are men so vulnerable? Eur Arch Psychiatry Clin Neurosci. 2003; 253(1): $1-8$.

27. Wålinder J, Rutzt W. Male depression and suicide. Int Clin Psychopharmacol. 2001; 16(2): S21-24.

28. Oquendo MA, Bongiovi-Garcia ME, Galfalvy H, Goldberg PH, Grunebaum MF, Burke AK, et al. Sex differences in clinical predictors of suicidal acts after major depression: a prospective study. Am J Psychiatry. 2007; 164(1): 134-141.

29. Eurostat statistics. http://epp.eurostat.ec.europa.eu/portal/page/portal/ statistics/search_database (access: 2015.03.18).

30. Skog OJ. Alcohol consumption and mortality rates from traffic accidents, accidental falls and other accidents in 14 European countries. Addiction. 2001; 96(1): 49-58.

31. Twisk DA, Stacey C. Trends in young driver risk and countermeasures in European countries. J Safety Res. 2007; 38(2): 245-257.

32. Krzyżak M, Maślach D, Szpak A, Piotrowska K, Florczyk K, Skrodzka M, Owoc A, Bojar I. Trends of potential years of life lost due to main causes of deaths in urban and rural population in Poland, 2002-2011. Ann Agric Environ Med. 2015; 22(3): 564-571. 